\title{
Monoclonal Antibody 3F8
}

National Cancer Institute

\section{Source}

National Cancer Institute. Monoclonal Antibody 3F8. NCI Thesaurus. Code C2370.

A murine monoclonal antibody directed against the cell-surface, tumor-associated antigen gang lioside GD2. Vaccination with monoclonal antibody $3 F 8$ may stimulate a host cytotoxic immune response against tumors that express gang lioside GD2. (NCI04) 